\title{
Article \\ Stability Design of Air Vibration Isolation Device for a High Power Density Main Engine
}

\author{
Jingmin Zhao ${ }^{1,2}$, Wenjun Bu ${ }^{1,2}$, Liang Shi ${ }^{1,2, *}$ and Zechao Hu ${ }^{1,2}$ \\ 1 Institute of Noise \& Vibration, Naval University of Engineering, Wuhan 430033, China; \\ zjm15811556228@163.com (J.Z.); bwj_2005@163.com (W.B.); huzechao68@outlook.com (Z.H.) \\ 2 National Key Laboratory on Ship Vibration \& Noise, Wuhan 430033, China \\ * Correspondence: whhg_sl@126.com
}

check for updates

Citation: Zhao, J.; Bu, W.; Shi, L.; Hu, Z. Stability Design of Air Vibration Isolation Device for a High Power Density Main Engine. Symmetry 2021, 13, 1244. https://doi.org/10.3390/ sym 13071244

Academic Editor: Tomohiro Inagaki

Received: 6 June 2021

Accepted: 6 July 2021

Published: 10 July 2021

Publisher's Note: MDPI stays neutral with regard to jurisdictional claims in published maps and institutional affiliations.

Copyright: (c) 2021 by the authors. Licensee MDPI, Basel, Switzerland. This article is an open access article distributed under the terms and conditions of the Creative Commons Attribution (CC BY) license (https:/ / creativecommons.org/licenses/by/ $4.0 /)$.

\begin{abstract}
In order to improve the alignment stability of the air vibration isolation device of a highpowered main engine, we established a mechanical model for the air vibration isolation system and analyzed the alignment deviation of the device and the vibration decoupling conditions of the system. Additionally, an optimized design method for the dual-direction support of the air vibration isolators positioned symmetrically on the main engine was proposed. The resultant design showed that when compared to the conventional inclined support of air springs for the main engines onboard ships, the dual-direction support design proposed in this paper for air vibration isolation could eliminate the adverse effect of the output torque reaction on the alignment of the main engine and decouple the system to reduce the number of peaks in the frequency response of vertical force transmission. The optimized design could effectively improve the alignment performance of the device for tilted or swinging operating conditions and maintain the good alignment stability of the device when a single vertical support air spring fails. A single vertical support air spring failure mainly affects the stability of the main engine under the reaction of the output torque, especially the air springs arranged in the corner, while the air springs arranged in the middle have no effect. The optimized design could also improve the vibration isolation performance. This is important for the design of air spring vibration isolation devices for high power density main engines.
\end{abstract}

Keywords: high power density main engine; air vibration isolator; alignment stability; vibration decoupling; optimal design

\section{Introduction}

Air vibration isolators, using air as an elastic medium, have several advantages compared to other vibration isolation components such as metal spring vibration isolators, wire rope vibration isolators, and rubber vibration isolators. These advantages include a low natural frequency (as low as $\sim 2 \mathrm{~Hz}$ ), an adjustable stiffness, a wide load-bearing range, and the absence of "creep". The bearing capacity of air vibration isolators can be controlled by adjusting the working pressure of the air springs, and alignment state of the main engine can be achieved [1-3]. Lou et al. [4,5] derived the model for calculating the stiffness of singlebag rectangular air springs with auxiliary chambers based on the geometric changes of the shapes of the air springs and according to the laws of thermodynamics. They discovered that the vertical stiffness of an air spring was directly proportional to the pressure and the load, and that the load did not greatly affect the natural frequency. Their findings laid the foundation for the design and application of air vibration isolators. Xu et al. [6,7] studied the load-bearing characteristics, the general form of the stiffness model, and the stiffness calculation model of an air vibration isolator and they carried out a further technical investigation of large-load air vibration isolation technology. This technology is currently capable of producing a variety of ship-board high-capacity air vibration isolators with different models and parameters (shown in Figure 1). This capability has provided reliable air vibration isolators for large scale equipment such as the main engines on ships. However, 
due to some assumptions made in the establishment of the air spring stiffness model, as well as the lack of rigorous adherence to the design requirements in the manufacturing process of air vibration isolators, the stiffness calculation model is mainly used for the design stage of a vibration isolator, and it is not suitable for the engineering application stage [8]. Based on experimental data [9], Xu pointed out that the lateral, vertical, static, and dynamic stiffnesses of an air spring were generally linearly proportional to the air pressure, and that the stiffness of any air spring of the vibration isolation device could be calculated from the air pressure. Therefore, the stiffness calculation method of an air vibration isolator in the application process is mainly an identification model based on experimental data. The above research has laid the foundation for the design of air vibration isolators and vibration isolation devices applied to main engine vibration isolation systems.

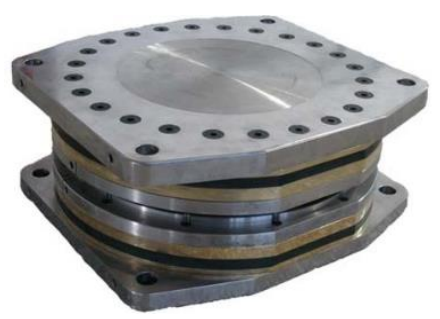

Figure 1. High load capacity air spring.

Air vibration isolation devices have been successfully applied to the main engines of ships with good stability [10]. Figure 2 shows a photograph of an air vibration isolation system prototype and its test rig. To further enhance the alignment stability and vibration damping effects of air vibration isolation devices on ships' main engines when the ship is tilted or swinging, $\mathrm{Xu}$ et al. analyzed the dynamic characteristic of the force transmission of an air vibration isolation device, and they noted that since the natural frequency of the air vibration isolator was lower than that of conventional rubber vibration isolators, its vibration isolation performance was far superior to that of rubber vibration isolation systems [11]. He et al. [10] established an analytical model for the alignment deviation of a main engine and analyzed the factors that affected the stability of the device. They found that for the design of the main engine air vibration isolation device, the location of the isolators needed to be as low as possible. Sun [12] analyzed the effects of the stiffness, position, and angle of the air springs on the alignment stability and carried out the optimization design of the vibration reducing parameters of an air vibration isolation device using genetic algorithms. Compared to a horizontally positioned vibration isolation system, the optimization results not only improved the alignment stability of the device, but also reduced its natural frequency. The above research can play a guiding role in the design of a main engine air vibration isolation device, but the main emphasis is placed on the alignment stability of the device when the hull is tilted.

At present, the air vibration isolation devices for main engines are mostly installed using the inclined support method, and many researchers have studied this type of support. Crede has analyzed inclined isolation devices with a symmetric layout to obtain the position of the elastic axis and the vibration decoupling condition [13]. The analysis shows that the vibration could be decoupled by judiciously configuring the structural parameters. Yan studied flat-mounted, radially mounted, converging-mounted, and inclined vibration isolation systems and found that the inclined configuration could not only reduce the center of gravity of the system, but also achieve vibration decoupling and ensure a higher transverse stiffness and roll flexibility by properly laying out the isolators [14]. Wang et al. [15] used the ratio of the difference between the two natural coupling frequencies of an inclined vibration isolation system and the vertical natural frequency of a horizontal vibration isolation system as the evaluation parameters to study the effects of the aspect ratio of the equipment, the inclination angle, and the ratio of the horizontal and vertical stiffnesses on the vibration isolation performance of the isolation system with inclined mounts. They fur- 
ther optimized the design and derived the matching relationship between the aspect ratio of the equipment, the stiffness ratio of the isolators, and the inclination angle to produce the optimal vibration isolation effect. Chen et al. [16] studied the coupled lateral-roll vibration characteristics and the decoupling characteristics of an inclined vibration isolation system, and they showed that the transfer of the vibration energy could be substantially reduced by decoupling the lateral-roll vibration. The above investigations have shown that for power systems with a large excitation force in the roll direction, such as the main engines on a ship [17], it is important to decouple the vibration isolation systems and to obtain the independent roll vibration when the inclined arrangement is adopted.

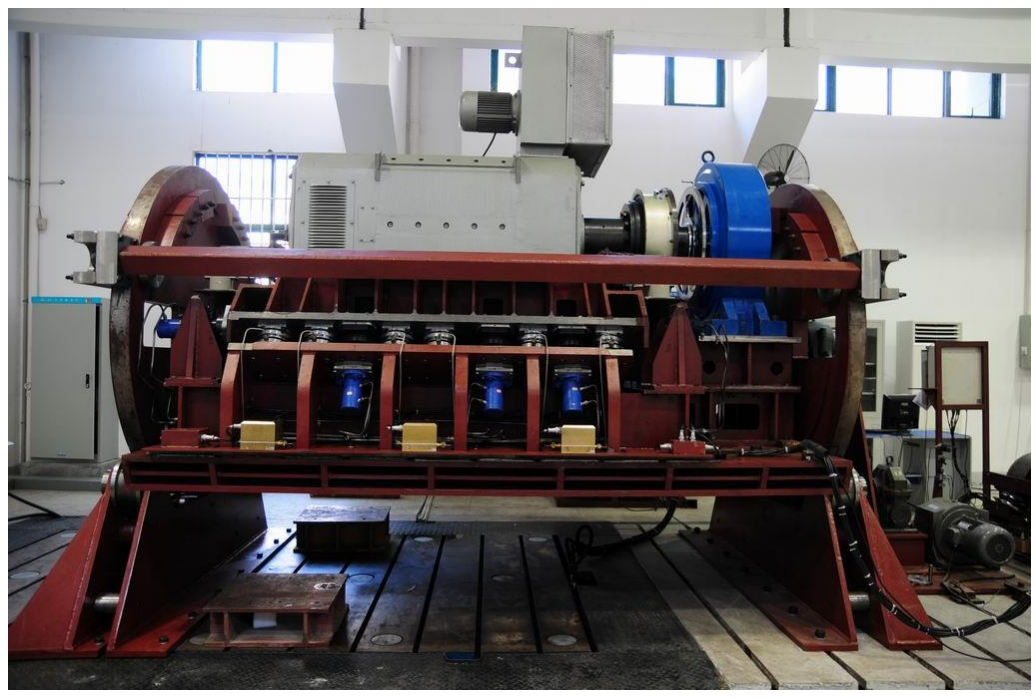

Figure 2. Photograph of the air vibration isolation system prototype and the test rig.

In engineering practice, the stability calculation of the vibration isolation device of a ship's main engine often involves the use of the maximum swing or tilt angle to calculate the static response [18]. The reasons for this are that: (1) A ship usually reaches the maximum swing period when it reaches the maximum swing angle. This rocking process can be regarded as a quasi-static process, which is equivalent to a tilted operating condition. (2) When a ship reaches its maximum rocking frequency, it usually reaches its smallest rocking amplitude. As a result, its impact on the stability of the vibration isolation device is much less than that of the large amplitude static swing. (3) A ship's highest swing frequency is less than $0.5 \mathrm{~Hz}$, which will not cause resonance of the vibration isolation device, and which has a small effect on the stability. The main effects of the main engine output torque on the stability of the vibration isolation device are: (1) The static displacement of the main engine caused by the DC component of the reaction of the output torque, and (2) The dynamic displacement of the main engine caused by the alternating torque reaction. Since the DC component of the output torque is much larger than its $\mathrm{AC}$ component, the fluctuating displacement caused by the AC component is relatively small, so in the design of the air vibration isolation device of the main engine, one usually considers only the static displacement change of the vibration isolation device caused by the DC component [9].

In previous studies, since the tilt or swing of a hull has a much greater effect on the stability of a main engine air vibration isolation device when compared with the output torque reaction of the main engine, in the design of a vibration isolation device, the main concern is to eliminate the adverse effects of the tilt or swing of a hull [10-12]. However, in the development of a propulsion system, some ship propulsion systems have adopted low-speed, high-power-density main engines [19]. The power of the main engine increases by more than ten times, but the volume and weight change minimally, and the deviation in alignment generated by the torque reaction in the continued use of the inclined air vibration 
system will also increase by ten times or more. This increases the mechanical noise of the axle system and jeopardizes the safe operation of the system. Additionally, in terms of the alignment control of the main engine, because of the strong coupling between the components of the alignment control, the deviation in alignment generated by the torque reaction increases the conflict between the control targets and lowers the controllability of the main engine alignment $[20,21]$. Since the alignment control device adopts fuzzy control or pulse control $[22,23]$, the alignment deviation caused by the reaction torque increases the adjustment amount or the number of adjustments of the air spring pressure required in the alignment control process, hence degrading the performance of the alignment control device. Therefore, unlike previous studies in which the main consideration has been the alignment stability of the device when the hull is tilted or swinging, in designing the alignment stability of the air vibration isolation devices for high power density main engines, emphasis should be placed on the effect of the output torque reaction.

In this research, we analyzed the alignment deviation generated by the output torque reaction and the decoupling condition of the system vibration by establishing a mechanical model of the air vibration isolation system. We proposed a dual-direction support for the air vibration isolators of a main engine and an optimized design method for the dual-direction support air vibration isolation device. The results showed that the dualdirectional support air vibration isolation device and its optimized design method played an important role in eliminating the adverse effects of the output torque reaction on the main engine alignment stability, improving the alignment stability of the device under operating conditions with tilt or oscillation, improving vibration isolation performance and maintaining good alignment stability in the event of the failure of a single vertical support air spring.

\section{Mechanical Model of Air Vibration Isolation System}

Figure 3 shows a schematic diagram of a certain type of marine main engine air vibration isolation system. Taking the center of gravity of the main engine as the origin of the coordinate and the output shaft of the motor as the positive y-direction, we established a global coordinate system that coincided with the centered state of the main engine, as shown in Figure 3. The air vibration isolators were positioned symmetrically with respect to the yoz plane and the $x o z$ plane, and they were located at the same height.
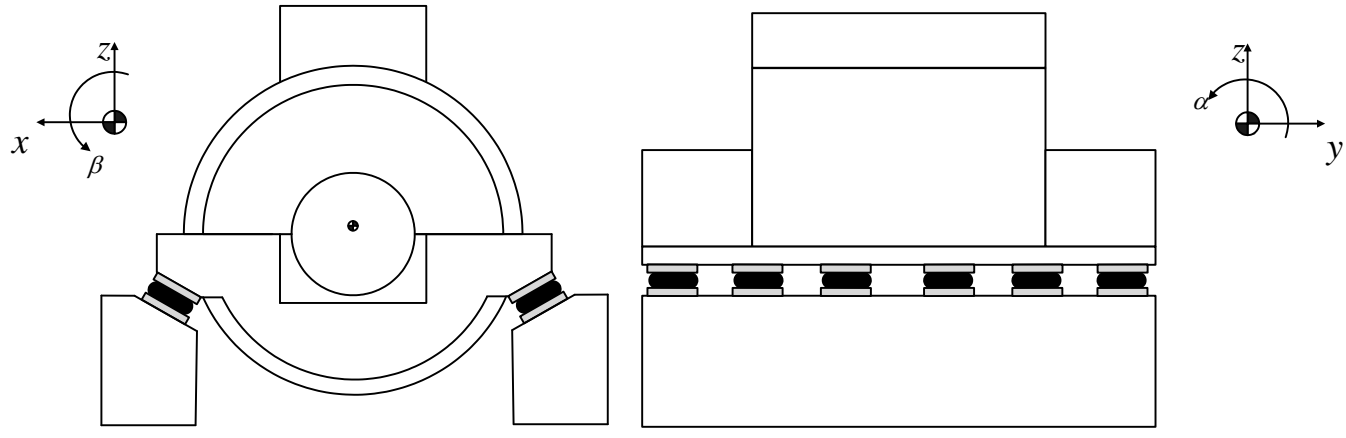

Figure 3. Schematic diagram of the air vibration isolation system of a main engine.

The main engine and the foundation were treated as rigid bodies, and each air vibration isolator was treated as a linear spring. The system could then be expressed with the dynamics equation [24]:

$$
\mathbf{M} \ddot{\mathbf{x}}_{g}+\mathbf{K} \mathbf{x}_{g}=\mathbf{F}
$$

where $\mathbf{M}$ is the mass matrix of the main engine, $\mathbf{x}_{\mathrm{g}}=\left[x_{g}, y_{g}, z_{g}, \alpha, \beta, \gamma\right]^{\mathrm{T}}$ is the displacement of the main engine center of gravity in the direction of the $x, y$, and $z$ coordinates as well as the angle of rotation of the main engine around the $x, y$, and $z$ axes, $\mathbf{K}$ is the global stiffness matrix of the system formed by the stiffness matrix of the isolators and the elastic coupler 
$\mathbf{K}=\left[\begin{array}{c}\sum_{i=1}^{n} k_{1}^{i} \\ 0 \\ 0 \\ 0 \\ \sum_{i=1}^{n}\left(-a_{x}^{i} k_{31}^{i}+a_{z} k_{1}^{i}\right) \\ 0\end{array}\right.$ after a coordinate transformation and $\mathbf{K}$ is a complex stiffness matrix when considering the damping, and $\mathbf{F}$ is the external force on the system.

By treating the effects of the external disturbance as a static process, one could obtain the displacement response of the main engine and the alignment of the main engine:

$$
\begin{aligned}
& \mathbf{x}_{g}=\mathbf{K}^{-1} \mathbf{F} \\
& \mathbf{x}_{c}=\mathbf{G}_{c} \mathbf{x}_{g}
\end{aligned}
$$

where $\mathbf{x}_{\mathrm{g}}=\left[x_{g}, y_{g}, z_{g}, \alpha, \beta, \gamma\right]^{\mathrm{T}}$ and $\mathbf{G}_{c}$ represents the position change matrix of the coupler.

Unless a vibration isolator is specifically designed to have a larger angular stiffness, the angular stiffness of the air vibration isolator can generally be ignored [25] and the stiffness of the coupler can be ignored. Since the air vibration isolators were located at the same height, the global stiffness matrix was:

$$
\left.\begin{array}{ccccc}
0 & 0 & 0 & \sum_{i=1}^{n}\left(-a_{x}^{i} k_{13}^{i}+a_{z} k_{1}^{i}\right) & 0 \\
\sum_{i=1}^{n} k_{2}^{i} & 0 & \sum_{i=1}^{n}\left(-a_{z} k_{2}^{i}\right) & 0 & 0 \\
0 & \sum_{i=1}^{n} k_{3}^{i} & 0 & 0 & 0 \\
\sum_{i=1}^{n}\left(-a_{z} k_{2}^{i}\right) & 0 & \sum_{i=1}^{n}\left(a_{z}^{2} k_{2}^{i}+a_{y}^{i} k_{3}^{i}\right) & 0 & 0 \\
0 & 0 & 0 & \sum_{i=1}^{n}\left(a_{x}^{i 2} k_{3}^{i}+a_{z}^{2} k_{1}^{i}-a_{x}^{i} a_{z} k_{13}^{i}-a_{x}^{i} a_{z} k_{31}^{i}\right) & 0 \\
0 & 0 & 0 & 0 & \sum_{i=1}^{n}\left(a_{x}^{i 2} k_{2}^{i}+a_{y}^{i 2} k_{1}^{i}\right)
\end{array}\right]
$$

where

$$
\left\{\begin{array}{l}
k_{1}^{i}=k_{p}^{i} \cos ^{2} \theta+k_{r}^{i} \sin ^{2} \theta \\
k_{2}^{i}=k_{q}^{i} \\
k_{3}^{i}=k_{p}^{i} \sin ^{2} \theta+k_{r}^{i} \cos ^{2} \theta \\
k_{13}^{i}=k_{31}^{i}=\operatorname{sgn}\left(a_{x i}\right)\left(k_{p}^{i}-k_{r}^{i}\right) \sin \theta \cos \theta
\end{array}\right.
$$

Here, $a_{x}^{i}, a_{y}^{i}, a_{z}$ are the coordinates of the $i$ th air spring in the global coordinate system, $k_{1}^{i}, k_{2}^{i}, k_{3}^{i}, k_{13}^{i}$ are the stiffness of the $i$ th air spring in the directions of the global coordinate, $k_{p}^{i}, k_{q}^{i}, k_{r}^{i}$ are the lateral, lateral, and vertical stiffness of the $i$ th air spring, $\theta$ is the inclination angle of the air vibration isolator, and $\operatorname{sgn}\left(a_{x i}\right)$ is the $\operatorname{sign}$ function of $a_{x}^{i}$, which was positive when $a_{x}^{i}$ was greater than zero and negative when $a_{x}^{i}$ was less than zero. Since the air spring was deployed symmetrically with respect to the yoz plane, $k_{13}^{i}$ and $a_{x}^{i}$ had equal magnitudes but opposite signs with respect to the yoz plane, while $a_{x}^{i} k_{13}^{i}$ had a unified sign. Since $k_{13}^{i}$ appeared as a product form in $a_{x}^{i} k_{13}^{i}$, the coupling stiffnesses of the air spring in the directions of the coordinate system were not ignored in $\mathbf{K}$ and $\mathbf{K}^{-1}$.

The relationship of the load capacity of the air vibration isolator with the pressure and the effective area was [6]:

$$
F=P S_{e}
$$

In the formula, $P$ is the gauge pressure of the gas in the air spring, and $S_{e}$ is the effective load-bearing area of the air vibration isolator. When the air spring was used at a constant height, the effective bearing area did not change. When the main engine was supported by multiple air springs, its load distribution was a statically indeterminate problem. In this research, the loads were distributed according to the principle of uniform 
distribution and optimized using the mean square error of the pressures in the different air springs as the objective function $[9,26]$, as shown in Equation (7):

$$
\left\{\begin{array}{cc}
\min & \left(\frac{1}{n} \sum_{i=1}^{n}\left(P_{i}-\bar{P}\right)^{2}\right)^{1 / 2} \\
\text { s.t. } & \sum_{i=1}^{n} P_{i} S_{e} \cos \theta=m g \\
& \sum_{i=1}^{n} P_{i} S_{e} a_{y}^{i}=0 \\
& \sum_{i=1}^{n} P_{i} S_{e} a_{x}^{i}=0 \\
l b \leq P_{i} \leq u b
\end{array}\right.
$$

Here, $P_{i}$ is the pressure of each air spring, $\bar{P}$ is the average pressure of $n$ air springs, and $l b$ and $u b$ are the allowable lower limit and upper limit of the air spring pressure, respectively.

The general calculation model for the vertical stiffness of the air vibration isolator was [6]:

$$
K=P \frac{d S_{e}}{d h}+n \frac{\left(P+P_{a}\right)}{V} S_{e}^{2}
$$

where $P_{a}$ is the atmospheric pressure, $V$ is the air spring volume, $n$ is the variable index of the gas change process, and $h$ is the vertical deformation of the air spring.

In this research, the stiffness of the air vibration isolator was calculated according to an air vibration isolator stiffness recognition model based on the experimental data:

$$
\begin{gathered}
k_{r}=\eta_{1} P+\eta_{2} \\
k_{p}=k_{q}=\eta_{3} P+\eta_{4}
\end{gathered}
$$

Here, $\eta_{\mathbf{r}}=\left[\begin{array}{ll}\eta_{1} & \eta_{2}\end{array}\right]^{T}$ and $\boldsymbol{\eta}_{p q}=\left[\begin{array}{ll}\eta_{3} & \eta_{4}\end{array}\right]^{T}$ are the vertical and horizontal stiffness model parameter vectors to be recognized.

By combining Equations (2)-(5), we obtained the changes of the alignment state with the reaction of the output torque:

$$
\begin{gathered}
x_{c}=\frac{\sum_{i=1}^{n} a_{x}^{i} k_{13}^{i}+\sum_{i=1}^{n} k_{1}^{i}\left(a_{z}^{c}-a_{z}\right)}{-\left(\sum_{i=1}^{n} a_{x}^{i} k_{13}^{i}\right)^{2}+\sum_{i=1}^{n} k_{1}^{i} \sum_{i=1}^{n} a_{x}^{i} 2 k_{3}^{i}} M_{x} \\
\beta=\frac{\sum_{i=1}^{n} k_{1}^{i}}{-\left(\sum_{i=1}^{n} a_{x}^{i} k_{13}^{i}\right)^{2}+\sum_{i=1}^{n} k_{1}^{i} \sum_{i=1}^{n} a_{x}^{i} 2 k_{3}^{i}} M_{x}
\end{gathered}
$$

Here, $M_{x}$ is the reaction of the output torque and $a_{z}^{c}$ is the vertical coordinate of the coupler. Similarly, one could obtain the alignment state changes for the heeling and trimming conditions:

$$
\begin{aligned}
& x_{c}=\frac{\sum_{i=1}^{n} k_{1}^{i}\left(a_{z}^{2}-a_{z} a_{z}^{c}\right)-\sum_{i=1}^{n} a_{x}^{i} k_{13}^{i}\left(2 a_{z}-a_{z}^{c}\right)+\sum_{i=1}^{n} a_{x}^{i} k_{3}^{i}}{-\left(\sum_{i=1}^{n} a_{x}^{i} k_{13}^{i}\right)^{2}+\sum_{i=1}^{n} k_{1}^{i} \sum_{i=1}^{n} a_{x}^{i} k_{3}^{i}} F_{x}^{h} \\
& z_{c}=\frac{F_{z}^{h}}{\sum_{i=1}^{n} k_{3}^{i}} \\
& \beta=\frac{\sum_{i=1}^{n} a_{x}^{i} k_{13}^{i}-\sum_{i=1}^{n} k_{1}^{i} a_{z}}{-\left(\sum_{i=1}^{n} a_{x}^{i} k_{13}^{i}\right)^{2}+\sum_{i=1}^{n} k_{1}^{i} \sum_{i=1}^{n} a_{x}^{i} 2 k_{3}^{i}} F_{x}^{h}
\end{aligned}
$$




$$
\begin{aligned}
& y_{c}=\frac{F_{y}^{t}}{\sum_{i=1}^{n} k_{2}^{i}}+\frac{a_{z}\left(a_{z}-a_{z}^{c}\right)}{\sum_{i=1}^{n} a_{y}^{i} k_{3}^{i}} F_{y}^{t} \\
& z_{c}=\frac{F_{z}^{t}}{\sum_{i=1}^{n} k_{3}^{i}}+\frac{a_{y}^{c} a_{z}}{\sum_{i=1}^{n} a_{y}^{i} 2 k_{3}^{i}} F_{z}^{t} \\
& \alpha=\frac{a_{z}}{\sum_{i=1}^{n} a_{y}^{i} 2 k_{3}^{i}} F_{y}^{t}
\end{aligned}
$$

where $F_{x}^{h}$ and $F_{z}^{h}$ are the lateral and vertical forces on the main engine when the hull was heeled, $F_{y}^{t}$ and $F_{z}^{t}$ are the longitudinal and vertical forces on the main engine when the hull was trimmed.

Equation (4) shows that there were independent vertical and yaw vibrations, coupled transverse-roll vibrations, and longitudinal-pitch vibrations. When the transverse-roll coupling stiffness was zero, the main elastic axis of the system passed through the center of gravity and the decoupling condition was given by:

$$
\sum_{i=1}^{n}\left(-a_{x}^{i} k_{13}^{i}+a_{z} k_{1}^{i}\right)=0
$$

Similarly, the decoupling condition for the longitudinal-pitch vibration was:

$$
\sum_{i=1}^{n}\left(-a_{z} k_{2}^{i}\right)=0
$$

\section{Optimized Design of Air Vibration Isolation Device}

\subsection{Optimization of the Layout of the Air Vibration Isolators}

In order to improve the alignment stability of the high-power-density main engine with the reaction of the output torque and to ensure the vibration isolation performance of the device, we proposed that the air vibration isolators should be used to provide the dualdirectional support of the main engine in both the vertical and the horizontal directions, as shown in Figure 4. In addition, by adjusting the installation position of the air spring and adjusting the center of mass of the main engine through adjusting the counterweights, the vertical installation distance $\left|a_{z}\right|$ of the air springs and the vertical coordinate of the coupler $a_{z}^{c}$ should be made to be zero; that is, both the isolator installation points and the coupler connection point had to be on the xoy plane. Based on Equations (4)-(9), a dual-directionally supported air vibration isolation device had the following advantages over an inclined isolation system:

1. When the air vibration isolators were supported in the vertical and horizontal directions, the inclination angles might be taken as $0^{\circ}$ and $90^{\circ}$; then $k_{13}^{i}$ would be zero. Additionally, when $a_{z}=a_{z}^{c}=0$, the lateral displacement $x_{c}$ with the reaction of the output torque was zero, which helped to raise the alignment stability of the device;

2. When $k_{13}^{i}=0$ and $a_{z}=0$, the decoupling conditions of the transverse-roll and longitudinal-pitch vibrations could be satisfied simultaneously. At that time, the vibrations of each direction of the system were independent, which was beneficial to the improvement of the vibration isolation performance of the device;

3. When $a_{z}=0$, the pitch stiffness $\sum_{i=1}^{n}\left(a_{z}^{2} k_{2}^{i}+a_{y}^{i} k_{3}^{i}\right)$ of the vibration isolation system was the smallest. At that time, the pitch mode had the lowest frequency, which was conducive to improving the vibration isolation performance of the system.

4. When the air springs supported the main engine vertically and laterally, the force on the main engine was also decoupled in different directions. At that time, the alignment deviation of the main engine in different directions could be controlled by adjusting the air spring pressure in different supporting directions, so that the coupling between the control targets was reduced. As the reaction torque no longer 
produced alignment deviation, the conflicts between the control targets were reduced, which was beneficial for improving the controllability of the alignment and the control performance of the device;

5. When the air springs supported the main engine both vertically and laterally, the lateral supports were under no load and they could provide pressure adjustments over a wider range. This increased the allowable range of the pressure adjustment of the lateral air springs in the alignment control, which helped improve the alignment control of the device.

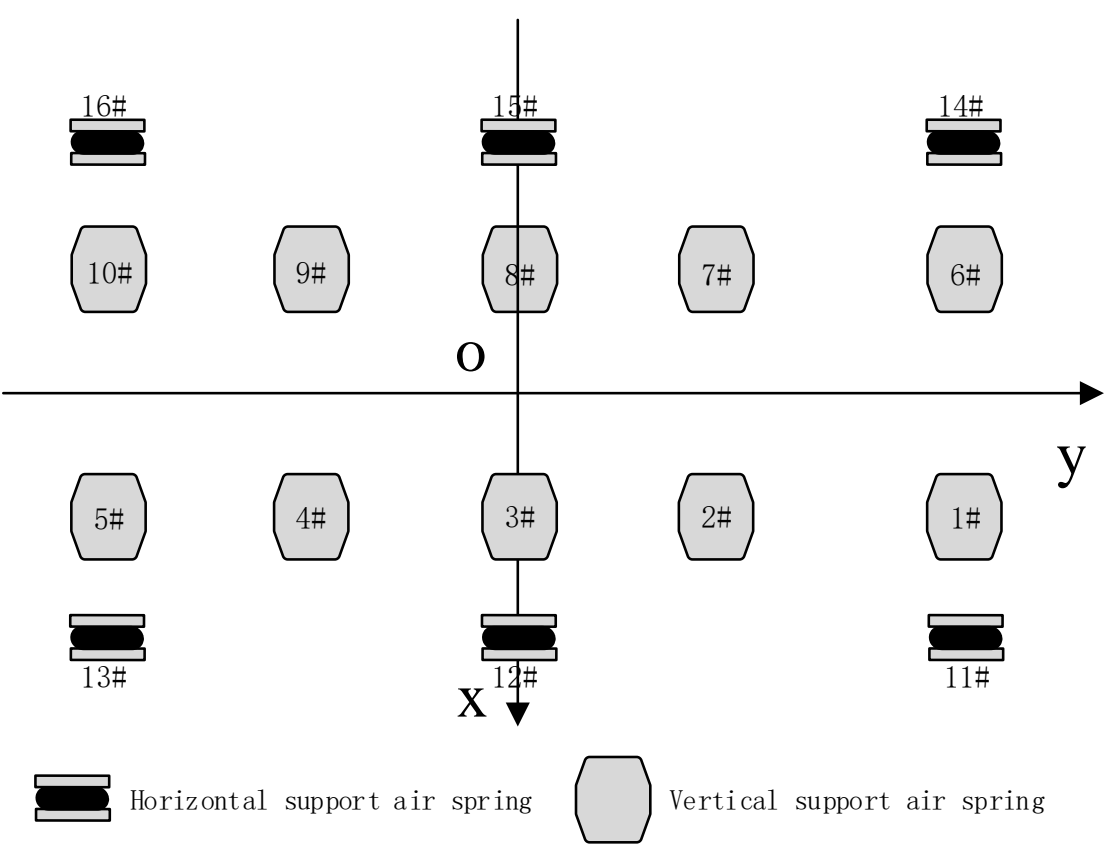

Figure 4. Schematic diagram of the dual-directional support air vibration isolation device.

\subsection{Optimized Design of Dual-Directional Support Air Vibration Isolation Device}

For a dual-directional support air vibration isolation device, the key to a successful design is to select the air spring parameters for the device to achieve good alignment and efficient isolation. The problem may be solved by searching for the optimal solution with nonlinear mathematical programming, and the problem involves multitarget optimization.

Since the vibration damping effect of the device depended to a large extent on the natural frequency of the system, we used the center deviation and the natural frequencies of the device under perturbed operating conditions as the optimization targets. We also used the weighting coefficients to convert the multiobjective optimization problem into a single target optimization problem for the following evaluation function $[27,28]$ :

$$
\left\{\begin{array}{cccc}
\min & f(x)=\sum_{i=1}^{n} w_{i} y_{c i} & & \text { (optimization target) } \\
\text { s.t. } & g l b_{i} \leq g_{i}(x) \leq g u b_{i} & i=1,2 \ldots 6 & \text { (inequality constraints) } \\
& x l b_{j} \leq x_{j} \leq x u b_{j} & j=1,2 \ldots m & \text { (boundary constraints) }
\end{array}\right.
$$

Here, $x=\left[x_{1}, x_{2}, \ldots, x_{m}\right]^{T}$ is the design parameter vector; $y_{c i}$ is the optimization target function; $w_{i}$ is the weighting coefficient; $g_{i}(x)$ is the natural frequency in the excitation direction and the alignment deviation; $g l b_{i}$ and $g u b_{i}$ are the lower limit and the upper limit of $g_{i}(x)$, respectively; $x l b_{j}$ and $x u b_{j}$ are the lower limit and the upper limit of each design parameter, respectively.

Based on the weight of the main engine, the rated load of the air spring, the installation space, the size of the air spring and the natural frequency, the model of an air spring can be determined in a preliminary sense. The vertical static stiffness properties of the air spring 
and the dynamic-static stiffness ratio are generally constant. The vertical air spring working pressure is given according to Equation (7), but its horizontal-vertical stiffness ratio can be designed. The design parameters may be chosen as the horizontal-vertical stiffness ratio of the vertical support air spring, the operating pressure of the lateral support air spring, and its horizontal-vertical stiffness ratio. The upper and lower limits can be determined according to the air spring production process and the range of air pressure permissible.

In extreme cases, such as in operating conditions on ships with a large-angle tilt or in large-angle swing, and in non-stealth working conditions, the main engine will be held rigidly by position-limiting and protective devices. Then, the air vibration isolation devices will no longer be in operation in order to ensure the safe operation of the propulsion system, to reduce the consumption of the alignment control system, and to improve the service life and reliability of the system $[9,29]$. Additionally, given that the performance of the vibration isolation device depends largely on the distribution of its natural frequencies, an ideal vibration isolation will be achieved if the natural frequencies of the system are all below the excitation frequency [30]. For this reason, we incorporated the excitation characteristics of the main engine and chose the optimization targets in this research to be the natural frequencies of the horizontal, vertical, and roll of the device, as well as the alignment deviations at the maximum roll and pitch angles of the device operating in the stealth mode.

In order to unify the dimensions of the single objective functions, the weight coefficients $w_{i}$ were chosen to be the reciprocals of the minimum values of the single objective functions. The lower and upper limits $g l b_{i}$ and $g u b_{i}$ of the natural frequencies in the stimulation direction and the alignment deviation were determined by combining the stimulation frequencies and the displacement compensation ability of the coupler in the actual operation of the main engine.

\section{Calculation Example Analysis}

We used the design optimization of a dual-direction support of an air vibration isolation device for a specific high-power-density main engine as an example of the analysis. Based on the number of air springs limited by the dimensions of the installation space and the size of the air spring, and the number of air springs required by the weight of the main engine and the rated load capacity of the air spring, and further considering the fact that the horizontal support air springs were not under a load, we made the preliminary choice of JYQN-6000 air springs as vertical support air springs and JYQN-5000 air springs as horizontal support air springs to ensure the effectiveness of the vibration isolation device. The parameters of the main engine and the isolators are listed in Table 1. The support modes were the inclined support mode and the dual-directional support mode proposed in this paper. The parameters of the air vibration isolation devices are listed in Table 2.

Table 1. Main engine and vibration isolator parameters.

\begin{tabular}{|c|c|c|c|c|c|c|c|c|c|}
\hline \multirow{3}{*}{$\begin{array}{c}\text { Main } \\
\text { Engine }\end{array}$} & \multirow{2}{*}{ Mass/t } & \multicolumn{6}{|c|}{ Product of Inertia $/ \mathrm{kg} \cdot \mathrm{m}^{2}$} & \multirow{2}{*}{\multicolumn{2}{|c|}{$\begin{array}{l}\text { Rated Output } \\
\text { Torque } / \mathrm{kN} \cdot \mathrm{m}\end{array}$}} \\
\hline & & Ixx & Iyy & Izz & Ixy & Ixz & Iyz & & \\
\hline & 50 & 71,500 & 50,000 & 64,000 & 0 & 0 & 0 & 981.5 & \\
\hline \multirow[t]{3}{*}{$\begin{array}{l}\text { Vibration } \\
\text { isolator }\end{array}$} & Model & $\begin{array}{l}\text { Rated } \\
\text { load/t }\end{array}$ & $\begin{array}{c}\text { Operation } \\
\text { load } \\
\text { range/t }\end{array}$ & $\begin{array}{c}\text { Rated air } \\
\text { pres- } \\
\text { sure/MPa }\end{array}$ & $\begin{array}{c}\text { Operation air } \\
\text { pressure } \\
\text { range/MPa }\end{array}$ & $\begin{array}{l}\text { Natural fre- } \\
\text { quency/Hz }\end{array}$ & $\begin{array}{l}\text { Dynamic and } \\
\text { static } \\
\text { stiffness ratio }\end{array}$ & $\begin{array}{c}\text { Horizontal- } \\
\text { vertical } \\
\text { stiffness ratio }\end{array}$ & $\begin{array}{l}\text { Damping } \\
\text { ratio }\end{array}$ \\
\hline & JYQN-6000 & 6 & $3-8$ & $\sim 1.5$ & $0.75-2$ & $\sim 5.5$ & $\sim 1.43$ & $1.0-2.4$ & 0.06 \\
\hline & JYQN-5000 & 5 & $2.5-6$ & $\sim 1.0$ & $0.5-1.2$ & $\sim 4.8$ & $\sim 1.15$ & $1.0-2.4$ & 0.06 \\
\hline
\end{tabular}


Table 2. Parameters of air vibration isolation device with two support methods.

\begin{tabular}{|c|c|c|c|c|c|}
\hline & Number of Air Springs & $\begin{array}{l}\text { Average Load } \\
\text { of Air Spring/t }\end{array}$ & $\begin{array}{c}\text { Vertical } \\
\text { Installation } \\
\text { Distance/mm }\end{array}$ & $\begin{array}{c}\text { Horizontal } \\
\text { Installation } \\
\text { Distance/mm }\end{array}$ & $\begin{array}{c}\text { Vertical } \\
\text { Coordinate of } \\
\text { Coupler/mm }\end{array}$ \\
\hline Inclined support at $30^{\circ}$ & 12 & 4.81 & 770 & 1319 & -70 \\
\hline Dual-direction support & 10 (vertical) + 6 (horizontal) & 5 (vertical) & 0 & 1319 & 0 \\
\hline
\end{tabular}

The number of air springs used to assume the vertical load in the dual-direction support was based on the average load-bearing capacity of the air springs, and the number of horizontal support air springs was based on the reliability requirement of the control device. In total, six horizontal support air springs were installed at the four corners and on the two sides of the main engine. It could be ensured that the vertical coordinate of the coupler was at zero by properly adjusting the positions and weight of the counterweights of the cooling air fans to change the center of mass of the main engine, including the counterweights.

\subsection{Alignment Stability}

Using the horizontal-vertical stiffness ratio of the air spring and the operating pressure of the horizontal air spring as design parameters, we applied the design optimization method described in Section 2 and we obtained a horizontal-vertical stiffness ratio of 2.4 for the vertical support air springs and a horizontal-vertical stiffness ratio of 1.0 for the horizontal support air springs; the obtained operating air pressure for the horizontal support air springs was $0.50 \mathrm{MPa}$. The displacement of the main engine output terminal with the disturbance of the output torque reaction and a listed hull in the stealth operating condition is shown in Figures 5-7.

Hence, unlike the inclined support of the air vibration isolator, when the dual-direction structure was adopted and the vertical mounting distance $\left|a_{z}\right|$ and the vertical coordinate of the coupler $a_{z}^{c}$ were both 0 , the output terminal of the main engine with the reaction of the output torque no longer generated the alignment deviation, which eliminated the adverse effect of the output torque on the alignment performance of the main engine.

With the optimization method proposed here, although the vertical offset of the main engine when the ship heeled $10^{\circ}$ went up by $2.27 \%$, the lateral offset was reduced by $55.32 \%$, resulting in a $55.07 \%$ reduction in alignment deviation. The longitudinal offset of the main engine when the ship trimmed $10^{\circ}$ was reduced by $39.13 \%$, the vertical offset was reduced by $90.28 \%$, resulting in a $48.47 \%$ reduction in alignment deviation. Therefore, the alignment performance of the device was improved on a tilted or swaying ship.

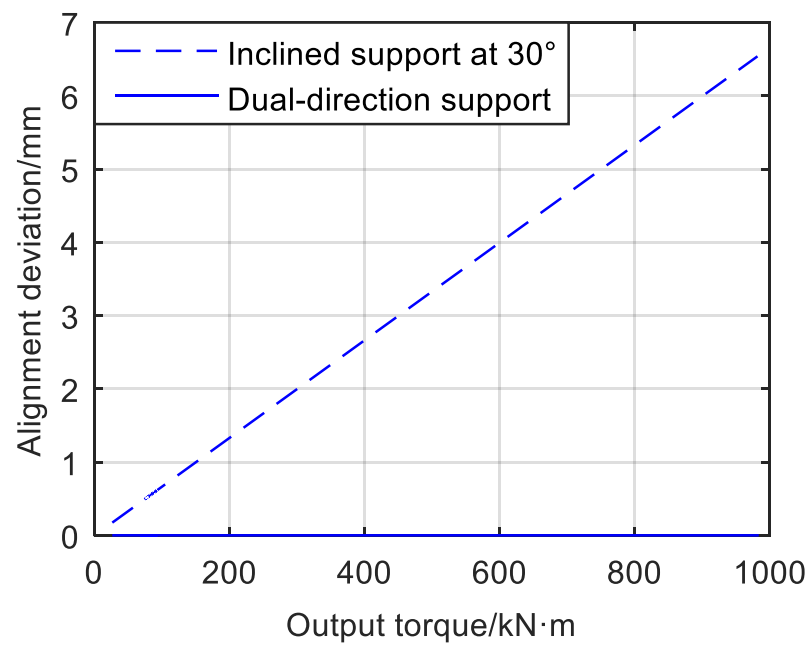

Figure 5. Displacement of the output terminal of the main engine with the reaction of the output torque. 


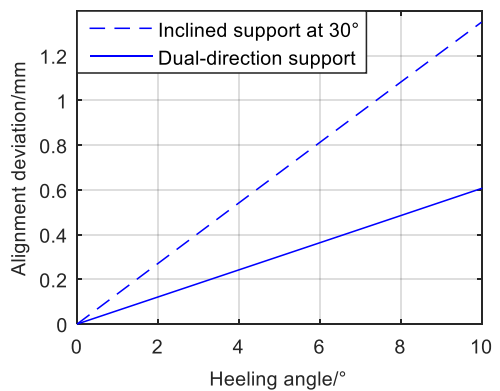

(a)

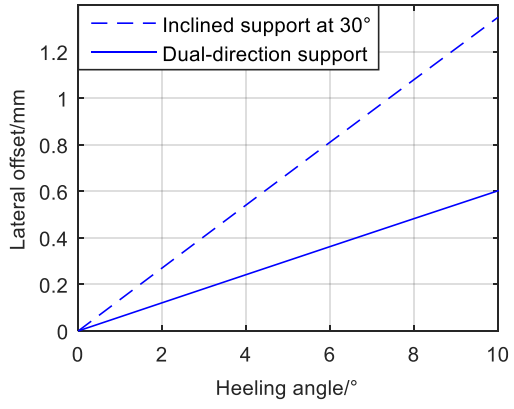

(b)

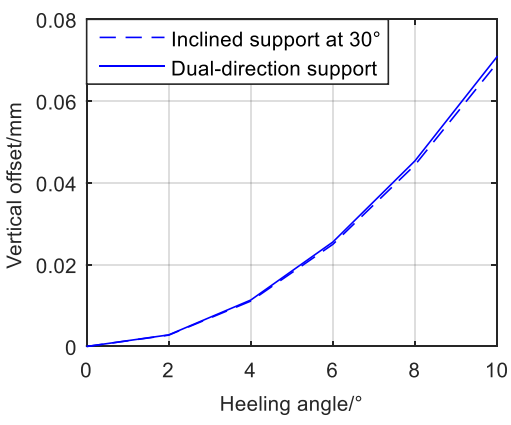

(c)

Figure 6. Displacement of the output terminal of the main engine when the hull was heeled. (a) Alignment deviation of the output terminal of the main engine when the hull was heeled; (b) Lateral offset of the output terminal of the main engine when the hull was heeled; (c) Vertical offset of the output terminal of the main engine when the hull was heeled.

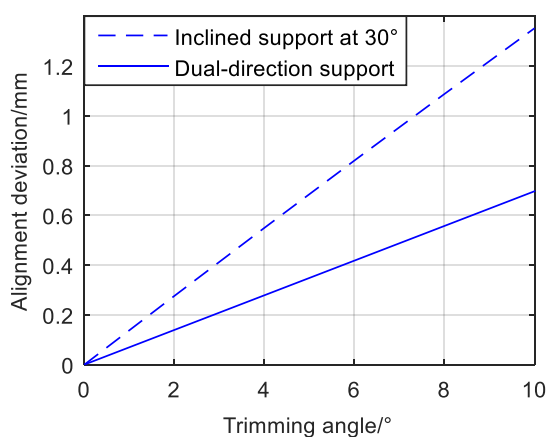

(a)

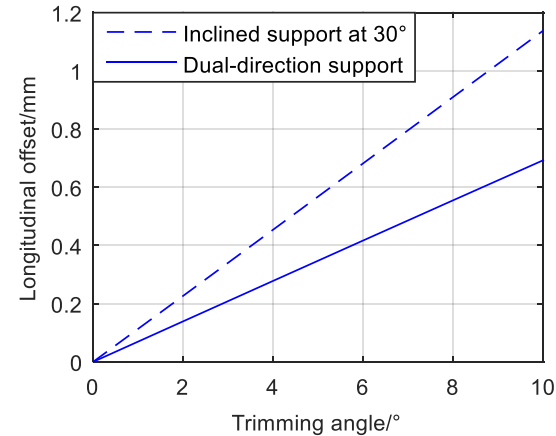

(b)

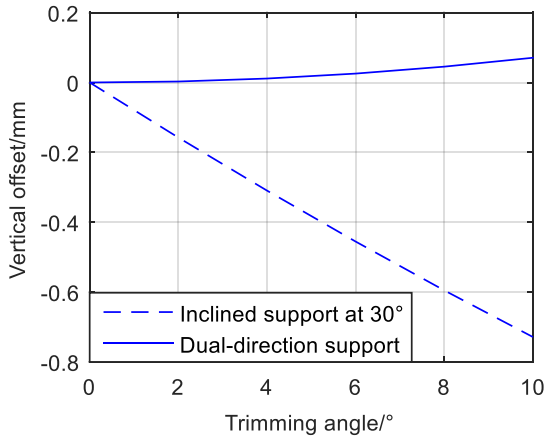

(c)

Figure 7. Displacement of the output terminal of the main engine when the hull was trimmed. (a) Alignment deviation of the output terminal of the main engine when the hull was trimmed; (b) Longitudinal offset of the output terminal of the main engine when the hull was heeled; (c) Vertical offset of the output terminal of the main engine when the hull was trimmed.

\subsection{Aligning Stability under Different Load Distribution Modes}

In extreme cases, individual air springs can be incapacitated by severe malfunctions. The horizontal support air springs do not bear the weight of the main engine. Therefore, when one horizontal support air spring fails, the force balance of the main engine can be ensured by unloading the air spring at the symmetrical position of the yoz plane. However, the vertical support air springs are used to carry the weight of the main engine, so in the event of failures of the vertical support air springs, the load of the main engine needs to be redistributed among the remaining air springs to maintain the operation of the vibration isolation system. Therefore, it is necessary to study the influence of the change in the vertical support air springs' load distribution on the alignment stability of the vibration isolation system. This paper studies the alignment stability of the vibration isolation device when a single vertical support air spring fails.

As the air springs are symmetrically arranged on the plane $x o z$ and yoz, only the influence of first, second or third air spring failure on the stability of the vibration isolation device is studied. It is assumed that the air spring number is shown in Figure 4 and the load of the air springs is distributed according to the modes shown in Table 3. Modes 1-4 represent all air springs in normal operation, and in first, second, or third air spring failure, respectively. 
Table 3. Load distribution of air springs.

\begin{tabular}{cccccc}
\hline \multirow{2}{*}{ Mode } & \multicolumn{5}{c}{ Load of Air Springs/t } \\
\cline { 2 - 6 } & $\mathbf{1 \# / 6 \#}$ & 2\#/7\# & 3\#/8\# & 4\#/9\# & 5\#/10\# \\
\hline 1 & 5.27 & 5.27 & 5.27 & 5.27 & 5.27 \\
2 & $0.00 / 6.98$ & $7.91 / 6.17$ & $7.02 / 5.27$ & $6.12 / 4.37$ & $5.30 / 3.56$ \\
3 & $7.41 / 5.99$ & $0.00 / 5.65$ & $6.68 / 5.27$ & $6.30 / 4.89$ & $5.96 / 4.55$ \\
4 & $6.59 / 5.27$ & $6.59 / 5.27$ & $0.00 / 5.27$ & $6.59 / 5.27$ & $6.59 / 5.27$ \\
\hline
\end{tabular}

Tables 4-6, respectively, show the alignment stability of the air vibration isolation device when the hull was heeled, trimmed and with the reaction of the output torque under the above four load distribution modes.

Table 4. Alignment deviation $(\mathrm{mm})$ of the air vibration isolation device when the hull was heeled with a single air spring failure.

\begin{tabular}{|c|c|c|c|c|c|}
\hline Mode & 0 & 2 & 4 & 6 & 8 \\
\hline 1 & 0.000 & 0.121 & 0.242 & 0.364 & 0.485 \\
\hline 2 & 0.000 & 0.121 & 0.241 & 0.362 & 0.483 \\
\hline 3 & 0.000 & 0.121 & 0.243 & 0.364 & 0.486 \\
\hline 4 & 0.000 & 0.122 & 0.243 & 0.365 & 0.487 \\
\hline
\end{tabular}

Table 5. Alignment deviation ( $\mathrm{mm}$ ) of the air vibration isolation device when the hull was trimmed with a single air spring failure.

\begin{tabular}{|c|c|c|c|c|c|}
\hline Mode & 2 & 4 & 6 & 8 & \\
\hline 1 & 0.000 & 0.139 & 0.279 & 0.418 & 0.557 \\
\hline 2 & 0.000 & 0.139 & 0.279 & 0.418 & 0.557 \\
\hline 3 & 0.000 & 0.139 & 0.279 & 0.418 & 0.557 \\
\hline 4 & 0.000 & 0.139 & 0.279 & 0.418 & 0.557 \\
\hline
\end{tabular}

Table 6. Alignment deviation $(\mathrm{mm})$ of the air vibration isolation device with the reaction of the output torque with a single air spring failure.

\begin{tabular}{|c|c|c|c|c|c|c|c|c|c|}
\hline Mode & Torque $/ \mathbf{k N} \cdot \mathbf{m}$ & 26.05 & 30.88 & 45.84 & 63.67 & 92.56 & 67.54 & 290.65 & 981.53 \\
\hline & 1 & 0.000 & 0.000 & 0.000 & 0.000 & 0.000 & 0.000 & 0.000 & 0.000 \\
\hline & 2 & 0.038 & 0.045 & 0.067 & 0.093 & 0.135 & 0.099 & 0.424 & 1.431 \\
\hline & 3 & 0.015 & 0.017 & 0.026 & 0.036 & 0.052 & 0.038 & 0.165 & 0.556 \\
\hline & 4 & 0.000 & 0.000 & 0.000 & 0.000 & 0.000 & 0.000 & 0.000 & 0.000 \\
\hline
\end{tabular}

By comparing the alignment stability of any air spring failure with that of the vibration isolation device in normal mode, it can be seen that the alignment stability of the motor is basically the same under the heeling and trimming conditions when an air spring failure occurs. However, the motor's alignment stability becomes very different with the reaction of the output torque. Under the condition of maximum output torque, the displacement of the main engine output terminal is $0 \mathrm{~mm}$ when the third air spring fails, $0.556 \mathrm{~mm}$ when the second air spring fails, and $1.431 \mathrm{~mm}$ when the first air spring fails, which is still less than the alignment deviation when the air springs are supported obliquely under normal working conditions.

This indicates that a single vertical air spring failure mainly affects the stability of the main engine under the reaction of output torque, especially the air springs arranged in the corner, while the air springs arranged in the middle have no effect. This is caused by the fact that when a single air spring fails, the air spring and its load distribution are 
no longer symmetric about the plane xoz and yoz, which affects the form of the system stiffness matrix in Equation (4).

\subsection{Vibration Isolation Performance}

The natural frequencies of the device in the inclined support configuration and the optimized dual-direction support configuration are shown in Table 7. Since the vibrations transmitted to the base of the machinery were mainly the bending waves generated by the excitation force perpendicular to the base [31], we evaluated the vibration isolation performance of the dual-direction support of the air vibration isolation device based on the transmission characteristics of the vertical and horizontal forces. According to the measured data, the damping ratio of the air spring used in the program was 0.06 . With the action of the dynamic excitation forces and in the Z-direction and the X-direction, respectively, and the dynamic torque around the $Y$-axis, the frequency response curves for the horizontal and vertical forces were as shown in the curves in Figure 8.

Table 7. Natural frequency $(\mathrm{Hz})$ of vibration isolation device.

\begin{tabular}{cccccccc}
\hline Inclined Support at $30^{\circ}$ & Vertical & Roll I & Roll II & Pitch I & Pitch II & Yaw \\
& 7.53 & 5.39 & 15.23 & 5.83 & 12.25 & 14.45 \\
\hline \multirow{2}{*}{ Dual-direction support } & Vertical & Horizontal & Roll & Pitch & Longitudinal & Yaw \\
& 6.12 & 8.95 & 8.30 & 5.78 & 8.95 & 13.85 \\
\hline
\end{tabular}

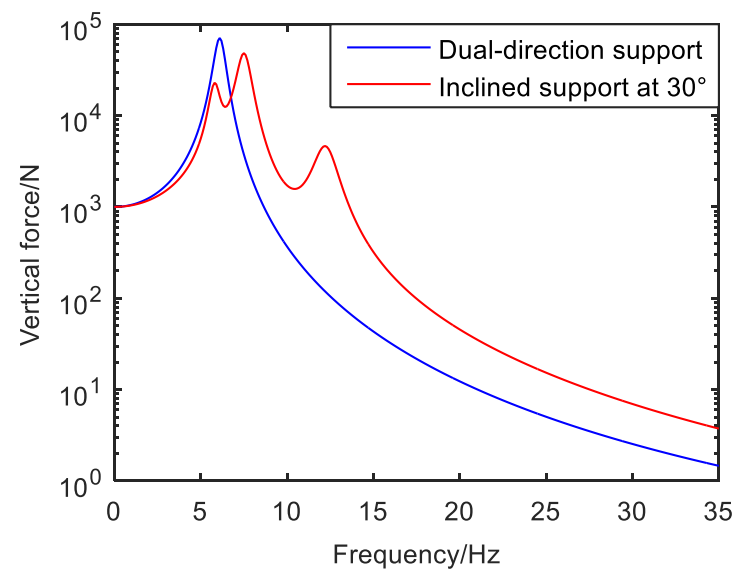

(a)

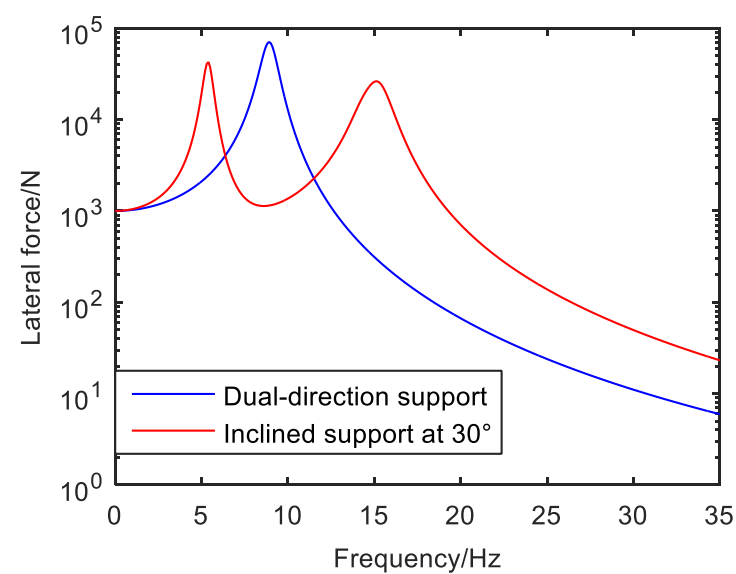

(b)

Figure 8. Dynamic response of the device before and after design optimization. (a) Frequency response of vertical force transmission; (b) Frequency response of lateral force transmission.

Hence, when the dual-direction structure was adopted and the vertical mounting distance $\left|a_{z}\right|$ and the vertical coordinate of the coupler $a_{z}^{c}$ were both 0 , the vibrations of the device in the various directions were decoupled, which was beneficial to the improvement of the vibration isolation performance of the device. The dynamic response results showed that air vibration isolation devices with dual-directional support could reduce the number of peaks in the transmitted force by decoupling the vibration of the system. With the optimized design, the natural frequency of the device could be further reduced to improve the vibration isolation at low frequencies.

\section{Conclusions}

Simulation experiments of alignment stability, aligning stability under different load distribution modes and vibration isolation performance were carried out for the dualdirection support design for the air vibration isolators of a main engine and the optimized design method for the dual-direction support air vibration isolation device proposed in this paper. In this regard, the main conclusions are summarized as follows: 
(1) This design avoids the effects of the output torque reaction on the alignment of the device. That means the reaction torque no longer produced alignment deviation, which is important for the application of airbag vibration isolation device to high power density main engines.

(2)The optimized design not only improved the alignment stability of the main engine with the ship operating in tilted or swinging conditions compared to vibration isolation devices supported by inclined air springs, but also could maintain the good alignment stability of the device when a single vertical support air spring failed. It means the design can improve the alignment stability of the device under various disturbance conditions and keep the propulsion system safe even if a single vertical support air spring fails. Additionally, special attention should be paid to the safe working condition of the air springs located in the corner of the application because they have a greater effect on the stability of the main engine under the reaction of the output torque.

(3) The various terms of vibration of the dual-direction support air vibration isolation device become decoupled to reduce the number of peaks in the transmitted force, which facilitates vibration control. Additionally, the optimized design enhanced the vibration isolation performance, which served as an important reference for the design of the air vibration isolation devices of high power density main engines.

(4) As the reaction torque no longer produced alignment deviation and the coupling of the various control targets was reduced, the conflicts between the control targets were reduced, which was beneficial for improving the controllability of the alignment and the control performance of the device.

Author Contributions: Conceptualization, J.Z., W.B., L.S. and Z.H.; methodology, J.Z., W.B.; software, J.Z., Z.H.; validation, J.Z., W.B., L.S. and Z.H.; formal analysis, J.Z.; data curation, J.Z.; writingoriginal draft preparation, J.Z. and L.S.; writing-review and editing, J.Z., W.B., L.S. and Z.H.; visualization, J.Z.; supervision, W.B. and L.S.; project administration, J.Z., W.B., L.S. All authors have read and agreed to the published version of the manuscript.

Funding: This research received no external funding.

Institutional Review Board Statement: Not applicable.

Informed Consent Statement: Not applicable.

Data Availability Statement: The data presented in this study are available on request from the corresponding author. The data are not publicly available due to privacy restrictions.

Conflicts of Interest: The authors declare no conflict of interest. The funders had no role in the design of the study; in the collection, analyses, or interpretation of data; in the writing of the manuscript, or in the decision to publish the results.

\section{References}

1. $\mathrm{Xu}, \mathrm{W}$. Research on Heavy-Load Air Vibration Isolation Technology. Ph.D. Thesis, Naval University of Engineering, Wuhan, China, 2004.

2. Zhang, Y.H. Springs; China Machine Press: Beijing, China, 1980.

3. Zhu, S.J.; He, L. Ship Vibration- and Noise-Reduction Technology and Engineering Design; Science Press: Beijing, China, 2002.

4. Lou, J.J.; Zhu, S.J. Stiffness calculation of rectangular air spring. Noise Vib. Control 2001, 4, $22-26$.

5. Lou, J.J.; Zhu, S.J. Single-bagged air spring's parameter calculation. J. Naval Univ. Eng. 2001, 13, 64-66. [CrossRef]

6. Wei, X.; Lin, H.; Geng, S.C.; Xia, Y.Z. Stiffness calculation and dynamic simulation of air spring. In ASME International Design Engineering Technical Conferences and Computers and Information in Engineering, Proceedings of the Conferences-DETC2005: 20th Biennial Conference on Mechanical Vibration and Noise, Long Beach, CA, USA, 25-28 September 2005; The American Society of Mechanical Engineers (ASME): New York, NY, USA, 2005; pp. 1395-1399.

7. Zhao, Y.L.; Lv, Z.Q.; He, L. Study of pneumatic vibration isolator of type JYQN. Ship Sci. Technol. 2006, 28, 89-92.

8. $\mathrm{Bu}, \mathrm{W} . J$. Alignment Monitoring and Control of Air Vibration Isolation Technology for Ship Propulsion Main Engine. Ph.D. Thesis, Naval University of Engineering, Wuhan, China, 2010.

9. $\mathrm{Xu}, \mathrm{W}$. Theoretical and Experimental Studies of Air Vibration Isolation Technology for Ship Propulsion Main Engine. Ph.D. Thesis, Naval University of Engineering, Wuhan, China, 2010. 
10. He, L.; Xu, W.; Bu, W.; Shi, L. Dynamic analysis and design of air spring mounting system for marine propulsion system. J. Sound Vib. 2014, 333, 4912-4929. [CrossRef]

11. Xu, W.; He, L.; Lv, Z.Q.; Li, T.Q. Dynamic analysis of an air spring mounting system for marine main engine. J. Vib. Shock 2007, 26, 122-125. [CrossRef]

12. Sun, J.Q. Parameter Optimization of Air Spring Vibration Isolation System Ship Main engine in Static Stability. Ph.D. Thesis, Xi'an University of Science and Technology, Xi'an, China, 2008.

13. Crede Charles, E. Vibration and Shock Isolation; John Wiley \& Sons Inc.: New York, NY, USA, 1951.

14. Yan, J.K. Machine Vibration Isolation Technology; Shanghai Scientific and Technical Publishers: Shanghai, China, 1986.

15. Wang, Q.J.; Song, K.J. Optimal Design of Inclined Vibration Isolation System. Noise Vib. Control 1992, 2, 8-12.

16. Chen, K.W.; Sun, L.L.; Wang, X.L.; Gao, Y. Study on coupled vibration characteristics of inclined isolation system. Noise Vib. Control 2014, 34, 72-75. [CrossRef]

17. Li, L.Y.; Cao, Y.P.; Zhang, Z.P. Impact of main engine vibration isolation on marine propulsion shafting transverse vibration under lateral rolling. J. Vib. Shock 2016, 35, 201-206. [CrossRef]

18. Pettersen, J.W.E.; Storm, J.F. (Eds.) Noise Control in Ships; NTNF Report B.0930.4502.1; Norwegian Council for Technical and Scientific Research: Oslo, Norway, 1975.

19. Zhao, X.Q.; Shuai, C.G.; Xu, W. On design of vibration-isolating system for high-power-density propulsion motor. J. Naval Univ. Eng. 2019, 31, 31-35. [CrossRef]

20. Shi, L.; He, L. Main engine air suspension system alignment control algorithm. J. Vib. Shock 2010, 29, 97-100. [CrossRef]

21. Bu, W.J.; He, L.; Shi, L. Alignment controllability of air spring vibration isolation system of a ship propulsion plant. J. Vib. Shock 2015, 34, 56-60. [CrossRef]

22. Bu, W.J.; Shan, S.J.; Hu, Z.C. Attitude control of statically indeterminate and multivariable coupling air spring vibration isolation system based on fuzzy controller. J. Vib. Shock 2007, 26, 174-177. [CrossRef]

23. Xu, W.; He, L.; Shi, L. Alignment disturbance control of an air-suspended main engine. J. Vib. Shock 2011, 30, 6-10. [CrossRef]

24. Harris, C.M.; Piersol, A.G. Shock and Vibration Handbook, 5th ed.; McGraw-Hill: New York, NY, USA, 2002.

25. Zhu, S.J. Vibration Theory and Vibration Isolation; National Defense Industry Press: Beijing, China, 2006.

26. Zhang, Y.; Xu, W.; Li, Z.; Yin, L. Alignment and safety analysis of marine propulsion shafting using intelligent floating raft system. J. Mar. Sci. Technol. 2020, prepublish. [CrossRef]

27. Sun, J.M. Mechanical Optimization Design; China Machine Press: Beijing, China, 2004.

28. Gao, N.; Wang, B.; Lu, K.; Hou, H. Teaching-learning-based optimization of an ultra-broadband parallel sound absorber. Appl. Acoust. 2021, 178, 107969. [CrossRef]

29. Hu, Z.C.; Xu, W.; He, L. On design of shock resistance of air spring vibration- isolating system for propulsion. J. Naval Univ. Eng. 2019, 31, 51-56. [CrossRef]

30. Gao, N.; Guo, X.; Deng, J.; Cheng, B.; Hou, H. Elastic Wave Modulation of Double-leaf ABH Beam Embedded Mass Oscillator. Appl. Acoust. 2021, 173, 107694. [CrossRef]

31. Tao, J.S. Design optimization of marine engine-mount system. J. Sound Vib. 2000, 235, 477-494. [CrossRef] 